\title{
Achieving with an Open Heart: How to Manage the Stress of Success
}

\author{
Arthur P Ciaramicoli* \\ Department of psychologist, USA
}

Submission: July 14, 2017; Published: July 21, 2017

*Corresponding author: Arthur P Ciaramicoli, Member of the American Psychological Association and the Massachusetts Psychological Association, Harvard Medical School, USA, Tel: 508-435-9535; Email: drarthurc@gmail.com

\section{Introduction}

A few weeks ago one of my patients was found unconscious by his wife lying on a barn floor with a rope around his neck. He got drunk, tried to hang himself from a rafter that fortunately collapsed. Mark is an extremely intense man. He is often overly absorbed in his work as a software salesman and seldom able to be present in a way that makes people feel he is listening and comprehending. In essence his empathic abilities are lacking and he has often been accused of being quite narcissistic. He had recently been laid off after not making his sales quota for the second straight quarter and was feeling humiliated and ashamed, common emotional states for narcissists when they fail.

Mark, despite this profile, is a decent person who is immensely miss-directed in his efforts to live a happy, fulfilled life. His father was accomplished in the business world, his mother worked full time as an administrative assistant and together they provided a secure financial life for he and his sister. Neither parent was particularly attuned to their children, both labeled poor listeners by Mark and preoccupied with their own interests. Thus you understand how he emerged with the mindset of providing but not attending to emotional needs of those close to him.

Ironically his attempt to take his own life has opened a door he had never passed through before. He has always thought of his wife as being with him for functional reasons. "I gave her a comfortable life, I not sure she would have stayed with me if I didn't work so hard, make the big bucks". He feels the same about his adult daughter, "I didn't attend many of her sporting events but I was always there to pay for a fancy vacation, let her buy expensive clothes, bought her a great car in high school, sent her to an expensive private college, she didn't have to borrow a cent". His daughter was in the middle of planning an expensive wedding when Mark lost his job, he hadn't even told her that he was laid off for fear she would be too disappointed. Mark has related to me in a similar fashion, often making jokes about paying me and asking if I would help him if he had no money, or "would you cast me to the curb Doc".

\section{An Attempt to End Life began a Different Life}

Ironically since Mark's attempt he has experienced a kind of love based on empathy and compassion that he had never been open to feel before. He could not believe how devastated his wife was when she feared he was dead. He finally realized that her love is undeniable as he saw in her eyes how very much she cares and how devastated she was finding him unconscious. He was amazed that his daughter came to him when she learned of his attempt and pleaded with him to let her cancel the current wedding plan. She had already begun changing the plan to a simpler occasion with just extended family and a few friends to reduce the pressure on him. He was even emotionally moved that I would extend my workday on several occasions to meet with him and his family. He felt pressured about not having insurance and when I remarked that I trusted him and knew he would pay me when he could he was emotionally moved. All in all Mark's narcissism began to melt in the face of overpowering empathy. He has a softer, more attentive presence now and he appears to have discovered a level of intimacy that he desperately wants to sustain. He has been longing for years to just feel loved for who he is not just for what he provides. He now knows that his speed of thought and constant need to be in action was all to win love. Mark is certainly not out of the woods but he does have a much clearer idea of what brings love. Empathic relating is surely a key variable.

\section{Empathy can Uncover and Change a Negative Story}

Empathy is certainly the antithesis of narcissism. Mark has become more empathic as he slowed down enough to fully experience the power and benefit of this capability. As a result his tendency to be self-absorbed has decreased markedly and he 
is committed to being more available to his family and friends, without the old tendency to drift away into his own world. Although his suicidal attempt is a rare occurrence his belief that performance will bring love and respect is part a cultural dynamic I call Performance Addiction, also the title of a book I wrote a few years ago. It is extremely common in our society and many who are afflicted have no idea of how to resolve the persistent unhappiness it causes. Without the ability to enter the world of another we remain self-absorbed and within ourselves. I have believed for years in the benefit of empathy training. Through empathic interactions we have the unique opportunity to rewrite our story by finding out, once and for all, the truth of who we really and what in life does really bring love and fulfillment. We are born with this capacity but whether it develops or not is dependent on how we are interacted with and how our models in the early years of our lives display their empathic attunement.
If you were not fortunate to have empathic parents or others who understood how to react from an empathic perspective you can still learn how to employ this important skill with the right training.

In our face paced culture many people have difficulty learning how to slow down and listen attentively. It is critical however to develop this skill as empathy is unquestionably the most important capacity for a successful personal and professional life. It is critical to maintaining intimacy and healthy working relationships. It allows us to see another accurately, to fall in love with a real person (real love) versus ill-fated attempts to love an image that can never be maintained over time. If we practice developing our empathic attunement to others we become part of the solution to a society that is drifting away to self-absorption. The health of our culture is dependent on our efforts. 